\title{
Testing the Present Value Model and Domino (Ripple) Effects for Hong Kong Private Residential Housing Prices
}

\author{
Kwok-Chiu Lam ${ }^{1}$ \\ ${ }^{1} \mathrm{PhD}$ Candidate in Finance, School of Finance, Shanghai University of Finance and Economics, China \\ Correspondence: Kwok-Chiu Lam, School of Finance, Shanghai University of Finance and Economics, 777 Guoding \\ Road, Shanghai, China
}

Received: July 2, 2015

Accepted: July 20, 2015

Online Published: August 20, 2015

doi:10.5430/ijfr.v6n4p22

URL: http://dx.doi.org/10.5430/ijfr.v6n4p22

\begin{abstract}
Under the assumptions of perfect market, house prices should theoretically conform to the present value model $(\mathrm{PVM})$, with expected future rents and discount rates being the two determinants. The objectives of this paper are twofold. First, to evaluate the PVM for Hong Kong private residential housing prices on submarket and territory-wide basis, under the premises of constant and nonconstant homeowner costs of capital. Following Meese and Wallace (1994) approach, we find that the PVM holds in the long run, though temporary deviations are likely. The Campbell and Shiller (1987) approach, on the contrary, generally supports the PVM. This paper would probably be the first examination to that end using Hong Kong empirical data. Second, Ho, Ma and Haurin (2008) find apparent uni-directional Granger-causal relationships (domino effects) along the quality tiers. We will explore not only such effects further on intraarea basis using more recent data, but also the intraclass ripple effects among the three geographical areas (Hong Kong Island, Kowloon, New Territories). We find that domino effects exist only marginally in the New Territories. On the other hand, the ripple effects do exhibit an interesting pattern that the origin of price change tends to shift along an area continuum as the house sizes increase. Lastly, regardless of whether price diffusions can be observed or not, house prices are generally found to be cointegrated in Hong Kong.
\end{abstract}

Keywords: present value model, domino effects, ripple effects, lead-lag relationships, cointegration, Hong Kong housing prices

\section{Introduction}

In finance theory, stock prices equate the discounted present value of expected future dividends to be received. If the PVM is correct, prices and dividends must be cointegrated. In their paper, Campbell and Shiller (1987) attempt to examine the validity of the PVM for stocks, showing that the results depend very sensitively on the discount rate assumed in the test and no conclusive evidence can be drawn. Taking the analogy with stocks, housing units can also be viewed as assets whose prices reflect capitalized rents. Literatures on the PVM for housing prices and cointegration among prices and/or rents for different countries are huge in quantity. For example, Meese and Wallace (1994) show that the PVM is, in the long run, valid and that house prices, rents, and homeowner costs of capital are cointegrated. Ong (1994) affirms the existence of cointegration amongst property stock prices, real estate prices and interest rate. Similar tests under different methodologies have been undertaken on US farmland (Tegene \& Kuchler, 1993; Engsted, 1998). A more recent study, Gallin (2008), also reveals that house prices and rents are cointegrated (the former tends to correct back to the latter).

Ripple effect refers to the spatial pattern that price shock in a region gradually diffuses to contiguous regions and then to more peripheral regions of the country over time. Numerous studies have been inspired on this in the context of different countries or regions since the 1990s. MacDonald and Taylor (1993) have segmented Britain into eleven regions and find that ripple effects do exist - price change first originates in Greater London and then transmits to other regions. Meen (1999) proposes four underlying reasons to elucidate the interregional ripple effects in Britain: (i) household migration due to price differences, (ii) equity transfer where individuals relocate to other low-price regions to repeat their purchases owing to higher equity, (iii) spatial arbitrage whereby financial flows among regions exhibit different paces in presence of search costs, and (iv) spatial growth patterns across the regions. Another study by Stevenson (2004) reveals substantial diffusion effects from Dublin to its neighboring markets within the Irish Republic. Again, interregional ripples in Britain are affirmed by Cook (2005) using confirmatory analysis 
supplemented with Monte Carlo simulation. Instead of viewing at the regional level, Jones and Leishman (2006) adopt a rather "micro" approach and ascertain the existence of the price ripples due to migrations amongst different local housing market areas in Strathclyde, a sub-region of Scotland. Chen, Chien, and Lee (2011) specifically test whether price diffusion is observable from Taipei City of Taiwan towards its suburban area of Taipei County, and also Taichung City and Kaohsiung City.

In contrast, published academic papers concerned with Hong Kong private residential housing prices are relatively few. Cheung, Tsang, and Mak (1995), using bivariate Granger-causality tests to investigate the lead-lag relationships between prices and rents in 20 submarkets in Hong Kong, find no such relationships in 29 out of the 40 cases. (Note 1) Out of the remaining 11 cases, 7 of them indicate that prices Granger-cause rents, 2 suggest the reverse direction, and 2 demonstrate bi-directional causality relationships. However, their examination tends to focus on short-term dynamic relations between the two series and leave the long-run cointegration possibilities unexplored. Also, no examination has been carried out on the potential (domino or ripple) causalities among all the submarkets. Ho, et al. (2008), using the broad territory-wide housing price indices, provide compelling evidence of uni-directional causal influences across units of different classes, following the order of smaller to larger sizes because of substitution or wealth effect. They describe the phenomenon as "price (domino) effects flowing through the quality continuum" (p.302). Their investigation is, however, not thorough enough, as no attempt has been made to explore such effects within each submarket. More importantly, little attention has been paid on the factor of interest rate movements in the aforementioned two studies.

There are two issues to be addressed in our paper. Firstly and primarily, to examine whether the PVM for private residential housing prices is true in Hong Kong. On this, our paper might probably be the first rigorous study, using both territory-wide and submarket empirical data; it is also unique that the movements of costs of capital have been taken into account systematically. Secondly, to extend the line of investigation about the price lead-lag relationships from territory-wide to submarket level. This paper is thus divided into part one and part two correspondingly, of which the structure is laid out as follows. Section 2 describes our two data sets and their denotations. Section 3 details our methodologies under the assumptions of constant and nonconstant costs of capital. Empirical findings are shared in Section 4. Lastly, limitations in this study are discussed, with concluding comments in Section 5.

\section{Data}

There are two data sets in our study. All data are retrieved on a monthly basis, unless otherwise specified. The first data set comprises (i) housing price index, (ii) rental index, and (iii) homeowner costs of capital. The entire sample period herewith covers from 1995M1 to 2014M12, with 240 monthly observations. The time-series index data are extracted from the online database of the Rating and Valuation Department (RVD) of the Hong Kong Special Administrative Region (HKSAR) Government. The costs of capital will be constructed later on.

In Hong Kong, all private residential units are officially disaggregated by the floor area exclusively allocated to the unit: Class A - less than $40 \mathrm{~m}^{2}$ (A), Class B - between $40 \mathrm{~m}^{2}$ and $69.9 \mathrm{~m}^{2}$ (B), Class C - between $70 \mathrm{~m}^{2}$ and $99.9 \mathrm{~m}^{2}$ (C), Class D - between $100 \mathrm{~m}^{2}$ and $159.9 \mathrm{~m}^{2}$ (D), and Class E - $160 \mathrm{~m}^{2}$ or above (E). (Note 2) While all price and rental indices are formulated on a territory-wide basis only, separate indices are available for each class, for both D and $\mathrm{E}$ (DE), and all classes (ALL) as well. We first deflate the price and rental indices for ALL using the composite consumer price index (originally scaled so that the 2009M10 - 2010M09 composite CPI equals 100) from the Census and Statistics Department (CSD) of HKSAR. They are then rescaled into the forms that take the value of 100 in 1995M01, denoted by "RPI" and "RRI" respectively. All growth rates are computed by taking the first logarithm differences of the variables (denoted with DL-prefix). For instance, the real growth rate of the composite price index for ALL is measured by:

$$
D L R P I_{t}=L R P I_{t}-L R P I_{t-1}
$$

where $\mathrm{LRPI}_{t}$ is the natural $\log$ transformation for RPI at time $t$.

Finally, assuming zero transaction costs, the real homeowner costs of capital in the housing market can be decomposed into various items with an adapted formula under Hong Kong case (Meese and Wallace 1994; Gallin 2008):

$$
k_{t}=\left(i_{t}+\omega_{t}^{r}\right)\left(1-\omega_{t}^{p}\right)+\delta_{t}+\varphi_{t}-\gamma_{t}
$$

where $k_{t}$ is the real homeowner costs of capital; $i_{t}$ is the nominal interest rate; $\omega_{t}^{r}$ is rates; $\omega_{t}^{p}$ is property tax rate; $\delta_{t}$ is depreciation rate; $\varphi_{t}$ is the risk premium on housing investment and $\gamma_{t}$ is expected rental inflation. (Note 3) We use the one-month Hong Kong Interbank Offered Rate (HIBOR) from the Bloomberg terminal as proxy for the nominal interest rate. Historical data is collected from RVD for rates, and Inland Revenue Department (IRD) 
for standard property tax rates. Following Meese and Wallace (1994), we assume that depreciation is 7\% per annum; risk premium is zero. In order to convert to the monthly basis, annual rates of depreciation, rates, and property tax are all divided by 12. (Note 4) The estimation procedure for the rental inflation will be elaborated further shortly.

Our second data set consists of (i) average house prices and (ii) average monthly rents for each class per $\mathrm{m}^{2}$ per geographical area. According to the RVD, average prices are based on an analysis of transactions scrutinized by the Department for stamp duty purposes. Average rents are based on an analysis of rental information (exclusive of rates and management charges) recorded for fresh lettings effective in the month being analyzed. Apart from the class categories above, average rents and prices are further sub-divided with respect to three different geographical areas of the Hong Kong territory: Hong Kong Island (HK), Kowloon (KWN), and the New Territories (NT). For inter- or intra- area analyses, we have to rely on our second (rather than the first) data set. The trade-off is that we must accept a relatively shorter sample period (i.e., 1999M1 to 2014M12, with 192 monthly observations). Beware that there are indeed no transactions recorded in some months for Class E, so we count only classes A, B, C and D in our second data set. Likewise, all average prices and rents are initially converted into real dollars using a factor of 100/CPI. More notations are now introduced for real prices and rents; for example, "HK_A_RP", "KWN_B_RR" and "NT_C_RP" represent the real price of class A unit located in Hong Kong Island, real rent of class B unit located in Kowloon, and real price of class $\mathrm{C}$ unit located in the New Territories, respectively. Since there are four individual classes and three areas, there are 12 submarkets and 12 pairs of data series for RP and RR.

\section{Methodology}

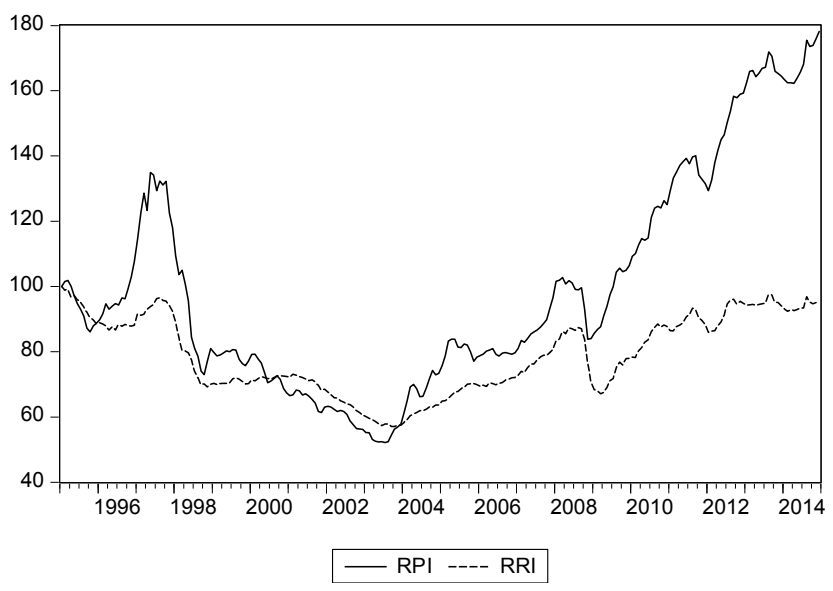

Figure 1. RPI vs. RRI (1995M1 - 2014M12)

Figure 1 provides graphical depictions of the time-series RPI and RRI between 1995M1 and 2014M12. It can be seen that the RPI has mounted by over 30 percent within two and a half years starting from 1995, before plummeting at end-1997 during the global financial crisis. Then the two series walk fairly close to each other. But since early 2004 the RPI begins to overtake RRI, and the gap tends to widen further after 2009. At first sight, we are tempted to state that the PVM is untrue because the two series are obviously not cointegrated during the past decade. This picture is, nonetheless, incomplete without considering interest rate (or costs of capital) movements. As expected, interest rates have been demonstrated to have negative impact on property prices (Ong, 1994). Hence, in part one of our study, the PVM will be investigated initially under the premise of constant costs of capital and then it is released. The methodologies we adopt draw on that established by Campbell and Shiller (1987), and in particular, Meese and Wallace (1994).

\subsection{Constant Cost of Capital ( $k$ )}

Under perfect market with rational expectations and zero transaction costs, the real expected returns from home ownership should be equal to the real costs of capital, which are assumed to be constant under this scenario. Meese and Wallace (1994) suggest that, if price returns are found serially correlated, the PVM is said to be violated in the short run. Accordingly, with our first data set in hand, we will use the following autoregressive model, AR(3), regressing the price return on a constant together with its own three lags, and then check the related F-statistic for the joint significance of the three lags. If the null hypothesis that $\theta_{1}=\theta_{2}=\theta_{3}=0$ is rejected, serial correlation is 
detected and the PVM is invalidated temporarily.

$$
D L R P I_{t}=\text { constant }+\theta_{1} D L R P I_{t-1}+\theta_{2} D L R P I_{t-2}+\theta_{3} D L R P I_{t-3}
$$

Alternatively, another more rigorous method to test the PVM is developed by Campbell and Shiller (1987) where stock price $P_{t}$ is expressed as:

$$
P_{t}=\varepsilon \sum_{i=0}^{\infty} \varepsilon^{i} E_{t} D_{t+i}
$$

where $D_{t}$ denotes stock dividend; $E_{t}$ denotes expectations; $\varepsilon$ is the discount factor equivalent to $(1+r)^{-1}$, where $r$ is the constant real rate of interest. If the price-dividend spread $\mathrm{S}_{\mathrm{t}}$ is defined as:

$$
P_{t}-r^{-1} D_{t-1}
$$

two of the ways proposed to examine the PVM for stocks is to check out if (i) $\mathrm{S}_{\mathrm{t}}$ is stationary, and (ii) $\mathrm{S}_{\mathrm{t}}$ positively Granger-cause dividend changes under the following bivariate vector autoregressive model (VAR):

$$
\left(\begin{array}{c}
\Delta D_{t-1} \\
S_{t}
\end{array}\right)=\left(\begin{array}{ll}
a(L) & b(L) \\
c(L) & d(L)
\end{array}\right)\left(\begin{array}{c}
\Delta D_{t-2} \\
S_{t-1}
\end{array}\right)+\left(\begin{array}{l}
u_{1 t} \\
u_{2 t}
\end{array}\right)
$$

where $a(L), b(L), c(L)$, and $d(L)$ are lag operators with polynomials of lag length $p$ and $u_{t}$ are i.i.d.. The answers should be affirmative to both of the questions above if the PVM holds. In contrast to Engsted (1998), we think it more appropriate to use real rents with no lag (i.e., $R_{\mathrm{t}}$ ) in defining the price-rent spread (Tegene \& Kuchler, 1993). That is, in our study, the spread in Equation 5 and bivariate VAR in Equation 6 are modified respectively as: (Note 5)

$$
\begin{gathered}
S_{t}=R P_{t}-r^{-1} R R_{t} \\
\left(\begin{array}{cc}
\Delta R R_{t} \\
S_{t}
\end{array}\right)=\left(\begin{array}{ll}
a(L) & b(L) \\
c(L) & d(L)
\end{array}\right)\left(\begin{array}{c}
\Delta R R_{t-1} \\
S_{t-1}
\end{array}\right)+\left(\begin{array}{l}
u_{1 t} \\
u_{2 t}
\end{array}\right)
\end{gathered}
$$

Our second data set plays an important role here, allowing us to carry out a more detailed investigation into the PVM for house prices within each submarket. As mentioned, the trade-off is that we must accept a smaller sample size of 192 monthly observations and some drawbacks to be mentioned under Limitations and Conclusions. Our tasks here are to test if (i) $S_{t}$ is stationary, and (ii) $S_{t}$ positively Granger-cause rental changes. There are several information criteria to help select the appropriate lag length $p$ under Granger-causality tests, for instance, the likelihood ratio (LR), Akaike information criterion (AIC), Schwarz Bayesian information criterion (SIC) and the Hannan-Quinn criterion (HQ). However, given our relatively small sample size, we would like to use SIC as the yardstick owing to its general better performance (Hacker \& Hatemi-J, 2008) and the serious limitations behind LR (Brooks 2010, p. 342).

\subsection{Nonconstant Cost of Capital $\left(k_{t}\right)$}

Considering the fact that the costs of capital can be time-varying because of changes in tax rates and borrowing costs, it is where our would-be costs of capital come into play. Meese and Wallace (1994) propose two criteria to be fulfilled in case the PVM is true: (i) the absence of serial correlation in the forecast (or present value) error using an AR(3) model, and (ii) the stationarity of the error, where the error is defined as:

$$
\varepsilon_{t+1}=R P I_{t+1}+R R I_{t+1}-R P I_{t}\left(1+k_{t}\right)
$$

Presence of serial correlation behind the errors imply that investors' expectations are simply irrational, and can be treated as short-term violation of the PVM. Nonetheless, if the errors are stationary, the PVM is upheld in the long run and the three component data series are said to be cointegrated. Using our first data set, we can carry out similar testings. (Note 6)

In part two of our study, we place similar restrictions as Cheung, et al. (1995), whereby correlations are hypothesised to be low across areas for intraarea analysis and across classes for intraclass analysis. In other words, we would not consider such lead-lag relationships across, for example, DHK_A_RP and DKWN_B_RP. To reiterate, our aim is to discern any potential price lead-lag relationships between different classes (domino effects) on intraarea basis and across different areas (ripple effects) on intraclass basis, using our second data set. Granger-causality tests in conjunction with VAR methodology have been extensively used on this. (Note 7) Of particular relevance here is the study by Ho, et al. (2008). We will deploy similar techniques, with lag length $p$ determined by SIC under a multivariate VAR. In case domino or ripple effects are detected, a necessary check is to conduct the Johansen test to assess whether there is a long-run cointegrating relationship across the areas or classes (Stevenson, 2004). If no cointegrating equation is found, then all such effects are supposed to exist only in the short run. 


\section{Empirical Findings}

The starting-point for our examination is to use Equation 2 to compute the costs of capital, by imposing a further assumption that the expected rental inflation follows a simple distributed lag of the past actual monthly rental inflation rates measured by the composite CPI for private housing rent from the CSD (Dougherty \& Van Order, 1982). Then we take a three-month lag to form the current rental inflation expectation, as below: (Note 8 )

$$
\gamma_{t}=0.000757+0.288256 \tilde{\gamma}_{t-1}+0.294047 \tilde{\gamma}_{t-2}-0.04949 \tilde{\gamma}_{t-3}
$$

where $\tilde{\gamma}_{t-i}$ is the actual monthly rental inflation rate of $i$ months ago and t-statistics of the parameters are reported in parentheses. Taken together with other aforementioned elements, a whole series of real costs of capital can be constructed herewith. Now we can kick off a series of examinations.

The second step is to test for stationarity of all the variables in our two data sets in levels and first differences, by conducting the following four tests: (i) augmented Dickey-Fuller test (ADF), (ii) modified Dickey-Fuller test (DF-GLS), (iii) Phillips-Perron (PP) test, and lastly (iv) KPSS stationary test. Cook (2005) criticizes ADF and PP tests as "lower-powered unit root tests" and encourages using DF-GLS coupled with KPSS stationarity test because DF-GLS has "an obvious appeal as it has been shown to possess the highest power of existing unit root tests" (p.612). In contrast, KPSS stationarity test reverses the null and alternative hypotheses, with stationarity under the null and a unit root under the alternative hypothesis. Their joint use is thus known as confirmatory analysis. For RPI and RRI, we take their logarithm (LRPI and LRRI) as levels so that their first differences (DLRPI and DLRRI) become the returns; and we include in test equations (maximum lag $=12$ ) with "intercept and trend." We do it in a similar way (but without taking log) for all submarket RP and RR. As for the cost of capital series, we will not take its log-form because it turned negative in late 2007. Furthermore, under economic theory there is no reason to assume it has a linear trend, so we include in test equation (maximum lag $=12$ ) with "intercept" only. Our rule of thumb (called "five-percent majority rule" thereafter) in interpreting all unit root (stationarity) test results is that if more than two test results showing the variable is (non-) stationary at 5\% significance level, it is interpreted as (non-) stationary; otherwise, inconclusive results are given. The test results (not shown here) indicate that LRPI, LRRI, COSTOFCAPITAL, and almost all submarket RP in levels are integrated of order one, I(1). (Note 9) As for RR, more ambiguous cases are found. (Note 10) But overall, we rest assured that most of the variables in levels in our data sets are I(1).

\subsection{Part One}

\subsubsection{Constant Cost of Capital $(k)$}

Using Equation 3 to check for autocorrelation in DLRPI, the following output is produced (with t-statistics reported in parentheses):

$$
\begin{aligned}
D_{L R P I_{t}}= & 0.0025+0.4706 D_{L R P I_{t-1}}-0.0222 D L R P I_{t-2}+0.0789 D L R P I_{t-3} \\
& (0.7656) \quad(7.2021) \\
\text { Adj. } \mathrm{R}^{2}= & 0.2248 ; \text { F-statistic }=23.71 ; \mathrm{DW}=2.01
\end{aligned}
$$

In the presence of lags of DLRPI, the DW is no longer reliable because it is biased towards 2. Instead, we should look at the F-statistic, which is 23.71; the p-value is much lower than 0.01 . This implies that the null hypothesis of all three lags jointly equal to zero should be rejected; therefore the PVM cannot hold in short term, meaning that RPI and RRI may drift apart from each other, as illustrated in Figure 1.

Alternatively, we can test the PVM by adopting Campbell and Shiller (1987) approach. Using Equation 7, the price-rent spread can be constructed by regressing RP on RR and saving the residuals. The reciprocal of the coefficient on RR becomes the estimate of $r$. Since most of the RP and RR have been found I(1), the spreads should be stationary if the PVM holds or prices and rents are truly cointegrated. Thus, cointegrating regressions are run between each pairing of RP and RR and the resultant spreads will firstly be tested for stationarity and then Granger-causality to rental changes. The R-squared values signify that the larger the size of the housing units, the lower is the explanatory power of RR on RP. Visually inspecting the plots of the 12 spreads (not shown here), it appears that class D spreads display linear trends. Therefore, for Class A to C spreads, we include only intercept in the test equations to check for stationarity; while for Class D, we include intercept with trend.

Again, we rely on the four different tests to check for stationarity for the price-rent spreads. Our five-percent majority rule indicates that all price-rent spreads are highly stationary, especially for those units located in NT. The 
real interest rate is shown to be ranging from $0.1466 \%$ to $0.3621 \%$ per month (or, from $1.7592 \%$ to $4.3452 \%$ per annum). Two inconclusive cases come from HK_C and HK_D. It appears that there is higher possibility that prices and rents can wander apart from each other for larger-sized units located in HK. Table 1 tabulates all the cointegrating regression and stationarity test statistics for the price-rent spreads.

Table 1. Cointegrating regressions and unit root (stationarity) tests for 12 price-rent spreads

\begin{tabular}{|c|c|c|c|c|c|c|c|}
\hline $\begin{array}{l}\text { Area \& } \\
\text { Class }\end{array}$ & Cointegrating regression & $\begin{array}{l}\text { Estimate } \\
\text { of } \mathrm{r}(\%)\end{array}$ & $\mathrm{R}^{2}$ & $\mathrm{ADF}$ & DF-GLS & PP & KPSS \\
\hline \multirow[t]{2}{*}{ HK_A } & $R P_{t}=-49687.09+454.89 R R_{t}$ & 0.2198 & 0.82 & $-4.3915 * * *$ & $-3.8822 * * *$ & $-4.5133 * * *$ & $0.4839 * *$ \\
\hline & $(-13.50) \quad(30.43)$ & & & & & & \\
\hline \multirow[t]{2}{*}{ KWN_A } & $R P_{t}=-48152.72+506.17 R R_{t}$ & 0.1976 & 0.84 & $-4.9120 * * *$ & $-4.9254 * * *$ & $-4.7409 * * *$ & $0.5180^{* *}$ \\
\hline & $(-16.12)$ & & & & & & \\
\hline \multirow[t]{2}{*}{ NT_A } & $R P_{t}=-29646.27+493.65 R R_{t}$ & 0.2026 & 0.92 & $-3.6379 * * *$ & $-3.5014 * * *$ & $-4.5323 * * *$ & 0.2102 \\
\hline & $(-20.15)$ & & & & & & \\
\hline \multirow[t]{2}{*}{ HK_B } & $R P_{t}=-52365.73+510.02 R R_{t}$ & 0.1961 & 0.84 & $-4.1874 * * *$ & $-4.1207 * * *$ & $-4.0911 * * *$ & $0.4950 * *$ \\
\hline & $(-13.72)$ & & & & & & \\
\hline \multirow[t]{2}{*}{ KWN_B } & $\mathrm{RP}_{\mathrm{t}}=-53104.88+578.90 \mathrm{RR}_{\mathrm{t}}$ & 0.1727 & 0.84 & $-4.6420 * * *$ & $-4.4786 * * *$ & $-4.4668 * * *$ & $0.3503 *$ \\
\hline & $(-16.02) \quad(32.42)$ & & & & & & \\
\hline \multirow[t]{2}{*}{ NT_B } & $R P_{t}=-25364.74+500.67 R R_{t}$ & 0.1997 & 0.87 & $-3.0797 * *$ & $-2.7174 * * *$ & $-4.2808 * * *$ & 0.2153 \\
\hline & $(-13.70)$ & & & & & & \\
\hline \multirow[t]{2}{*}{ HK_C } & $R P_{t}=-99727.59+652.93 R R_{t}$ & 0.1532 & 0.68 & -2.3654 & $2.3779 * *$ & $-3.8633 * * *$ & $0.8086^{* * *}$ \\
\hline & $(-10.83)$ & & & & & & \\
\hline \multirow[t]{2}{*}{ KWN_C } & $R P_{t}=-77756.10+676.43 R R_{t}$ & 0.1478 & 0.68 & $-3.6315 * * *$ & $-3.6406 * * *$ & $-7.9996 * * *$ & $0.9418 * * *$ \\
\hline & $(-10.37) \quad(20.53)$ & & & & & & \\
\hline \multirow[t]{2}{*}{ NT_C } & $R P_{t}=-27683.86+500.43 R R_{t}$ & 0.1998 & 0.73 & $-3.1204 * *$ & $-2.8913 * * *$ & $-5.0387 * * *$ & $0.7353^{* *}$ \\
\hline & $(22.76)$ & & & & & & \\
\hline \multirow[t]{2}{*}{ HK_D } & $R P_{t}=-111356.7+682.27 R R_{t}$ & 0.1466 & 0.63 & $-3.2122 *$ & $-3.0934 * *$ & $-4.9509 * * *$ & $0.1462 * *$ \\
\hline & $(-9.30) \quad(18.35)$ & & & & & & \\
\hline \multirow[t]{2}{*}{ KWN_D } & $\mathrm{RP}_{\mathrm{t}}=-59762.51+628.98 \mathrm{RR}_{\mathrm{t}}$ & 0.1590 & 0.41 & $-8.0437 * * *$ & -2.6010 & $-8.1215^{* * *}$ & $0.1256^{*}$ \\
\hline & $(11.57)$ & & & & & & \\
\hline \multirow[t]{2}{*}{ NT_D } & \multirow{2}{*}{$\begin{aligned} R P_{t}= & -25.05+276.16 R R_{t} \\
& (0.00)(11.35)\end{aligned}$} & 0.3621 & 0.40 & $-5.5157 * * *$ & $-3.4564 * *$ & $-10.3140 * * *$ & 0.0763 \\
\hline & & & & & & & \\
\hline
\end{tabular}

$*$,** and *** indicate significance at the critical value of $10 \%, 5 \%$ and $1 \%$, respectively. For KPSS test, the null hypothesis is $\mathrm{I}(0)$ while for other unit root tests, it is $\mathrm{I}(1)$. All tests are run using test equation (max lag 12$)$ with intercept only, except for HK_D, KWN_D and NT_D (with intercept and trend). t-statistics are reported in parentheses.

We then proceed to examine whether the spreads Granger-cause rental changes. Since all RR in first differences are stationary, we can resort to the Granger-causality tests with lag $p$ determined by SIC under the bivariate VAR in Equation 8. It is found that for all 12 submarkets, the null hypothesis that the spread does not Granger-cause rental change is strongly rejected at $5 \%$ significance level. Out of the 12 pairs of test results, 7 of them have showed uni-directional causality relationship from the spreads to rental changes; the remaining 5 have reflected bi-directional relationships. Thus, our test implications are rather striking in that the PVM holds in almost every submarket, implying that an equilibrium tends to be restored to bind the RP and RR series together, irrespective of the unit class or location. There are two suspicious cases from Class C and D units in HK, however. The Granger-causality test results are reported in Table 2. 
Table 2. Pairwise Granger-causality test results on price-rent spreads vs. rental changes

\begin{tabular}{|c|c|c|c|c|}
\hline $\begin{array}{c}\text { Bivariate } \\
\text { VAR Lag } p\end{array}$ & Null Hypothesis & F-Statistic & Probability & Causality \\
\hline \multirow[t]{2}{*}{1} & S_HK_A does not Granger Cause DHK_A_RR & $28.6294 * * *$ & $3 \times 10^{-7}$ & $\mathrm{~S} \rightarrow \Delta \mathrm{RR}$ \\
\hline & DHK_A_RR does not Granger Cause S_HK_A & 3.08222 & 0.0808 & \\
\hline \multirow[t]{2}{*}{1} & S_KWN_A does not Granger Cause DKWN_A_RR & $32.5173^{* * *}$ & $5 \times 10^{-8}$ & $\mathrm{~S} \rightarrow \Delta \mathrm{RR}$ \\
\hline & DKWN_A_RR does not Granger Cause S_KWN_A & 0.11314 & 0.7370 & \\
\hline \multirow[t]{2}{*}{1} & S_NT_A does not Granger Cause DNT_A_RR & $22.9978^{* * *}$ & $3 \times 10^{-6}$ & $\mathrm{~S} \leftrightarrow \Delta \mathrm{RR}$ \\
\hline & DNT_A_RR does not Granger Cause S_NT_A & $10.8186^{* * *}$ & 0.0012 & \\
\hline \multirow[t]{2}{*}{1} & S_HK_B does not Granger Cause DHK_B_RR & $25.0518^{* * *}$ & $1 \times 10^{-6}$ & $\mathrm{~S} \rightarrow \Delta \mathrm{RR}$ \\
\hline & DHK_B_RR does not Granger Cause S_HK_B & 0.04844 & 0.8260 & \\
\hline \multirow[t]{2}{*}{1} & S_KWN_B does not Granger Cause DKWN_B_RR & $22.3597 * * *$ & $4 \times 10^{-6}$ & $\mathrm{~S} \rightarrow \Delta \mathrm{RR}$ \\
\hline & DKWN_B_RR does not Granger Cause S_KWN_B & 1.46341 & 0.2279 & \\
\hline \multirow[t]{2}{*}{1} & S_NT_B does not Granger Cause DNT_B_RR & $26.2712 * * *$ & $7 \times 10^{-7}$ & $\mathrm{~S} \rightarrow \Delta \mathrm{RR}$ \\
\hline & DNT_B_RR does not Granger Cause S_NT_B & 0.00934 & 0.9231 & \\
\hline \multirow[t]{2}{*}{2} & S_HK_C does not Granger Cause DHK_C_RR & $6.59986^{* * *}$ & 0.0017 & $\mathrm{~S} \rightarrow \Delta \mathrm{RR}$ \\
\hline & DHK_C_RR does not Granger Cause S_HK_C & 2.85338 & 0.0602 & \\
\hline \multirow[t]{2}{*}{2} & S_KWN_C does not Granger Cause DKWN_C_RR & $7.98851 * * *$ & 0.0005 & $\mathrm{~S} \leftrightarrow \Delta \mathrm{RR}$ \\
\hline & DKWN_C_RR does not Granger Cause S_KWN_C & $5.16452 * * *$ & 0.0066 & \\
\hline \multirow[t]{2}{*}{1} & S_NT_C does not Granger Cause DNT_C_RR & $16.3757 * * *$ & $8 \times 10^{-5}$ & $\mathrm{~S} \leftrightarrow \Delta \mathrm{RR}$ \\
\hline & DNT_C_RR does not Granger Cause S_NT_C & $28.5929 * * *$ & $3 \times 10^{-7}$ & \\
\hline \multirow[t]{2}{*}{2} & S_HK_D does not Granger Cause DHK_D_RR & $5.29657 * * *$ & 0.0058 & $\mathrm{~S} \rightarrow \Delta \mathrm{RR}$ \\
\hline & DHK_D_RR does not Granger Cause S_HK_D & 2.65531 & 0.0730 & \\
\hline \multirow[t]{2}{*}{2} & S_KWN_D does not Granger Cause DKWN_D_RR & $3.5774 * *$ & 0.0299 & $\mathrm{~S} \leftrightarrow \Delta \mathrm{RR}$ \\
\hline & DKWN_D_RR does not Granger Cause S_KWN_D & $5.23561 * * *$ & 0.0061 & \\
\hline \multirow[t]{2}{*}{2} & S_NT_D does not Granger Cause DNT_D_RR & $6.69870^{* * *}$ & 0.0016 & $\mathrm{~S} \leftrightarrow \Delta \mathrm{RR}$ \\
\hline & DNT_D_RR does not Granger Cause S_NT_D & $3.12055^{* *}$ & 0.0465 & \\
\hline
\end{tabular}

** and $* *$ indicate significance at the critical value of $5 \%$ and $1 \%$, respectively.

Let us summarize that the Meese and Wallace (1994) approach suggests the PVM for house prices cannot be true in short run; while the Campbell and Shiller (1987) method provides considerable evidence supporting the validity of the PVM in the long run, although we cannot rule out the possibility of some deviations for larger-sized units located in HK.

\subsubsection{Nonconstant Cost of Capital $\left(k_{t}\right)$}

Violation of the PVM might be attributable to the fact that the costs of capital are varying, which can in turn be explained by changes in interest rate and tax rates (Meese and Wallace, 1994). They suggest incorporating that factor into the forecast error as defined earlier in Equation 9. The errors can be estimated with ease by running the regression using our first data set and then saving the residuals (denoted as $e_{t}$ ). Our next task is to check out if $e_{t}$ is serially correlated. The AR(3) technique is herewith repeated, regressing $e_{t}$ on a constant and its own three lags. As demonstrated below (with t-statistics reported in parentheses), F-statistic is 16.68 and p-value much smaller than 0.01. This indicates that the errors are autocorrelated, meaning that the PVM does not hold in short run again, even after taking into account that the costs of capital are time-varying.

$$
\begin{gathered}
e_{t}=0.0376+0.3440 e_{t-1}+0.0542 e_{t-2}+0.1250 e_{t-3} \\
(0.1058) \quad(5.2720) \quad(0.7865)
\end{gathered}
$$

Adj. $\mathrm{R}^{2}=0.1674 ;$ F-statistic $=16.68 ; \mathrm{DW}=2.01$ 
We move on to conduct unit root tests on $e_{t}$, where stationarity is detected. (Note 11) This in turn affirms the long-term validity of the PVM and the existence of cointegration between $\mathrm{RPI}_{\mathrm{t}}, \mathrm{RRI}_{\mathrm{t}}$, and $\mathrm{k}_{\mathrm{t}}$. This echoes our earlier caveat that cost of capital, as a key influencing factor of house prices, should preferably not be ignored in order to avoid hasty rejection of the PVM.

Since RP and RR have been previously found as cointegrated in almost all submarkets using Campbell and Shiller (1987) approach, it is logical to infer that adding the costs of capital $\mathrm{k}_{\mathrm{t}}$ would not affect the outcome, provided that variations in $\mathrm{k}_{\mathrm{t}}$ are stationary (which they are). $\mathrm{k}_{\mathrm{t}}$, also as the return from home ownership, can be decomposed into price return and rent-price ratio. By regarding rent-price ratio (RR/RP) as the rate at which future rents are discounted into current housing prices, $\mathrm{k}_{t}$ and $\mathrm{RR}_{\mathrm{t}} / \mathrm{RP}_{\mathrm{t}}$ should theoretically walk in tandem (i.e., they should be cointegrated) if the PVM is valid. As an illustrative example, we have put the time-series costs of capital versus the rent-price ratios for the HK_A submarket under Figure 2, with the left axis displaying the costs of capital in percentage and the right axis showing the rent-price ratios. It is noticeable that the two series really tend not to walk away too far from each other. Formally, because $k_{t}$ is $I(1)$ and $\Delta R P_{t}$ is $I(0)$, if $R R_{t} / R P_{t}$ is found $I(1), k_{t}$ and $R R_{t} / R_{t}$ are cointegrated. Testings for stationarity of all rent-price ratios are then implemented. Our five-percent majority rule reveals that all the rent-price ratios bar that for NT_D units which give inconclusive results, are I(1), as presented in Appendix 2. The results thus reinforce our earlier inference that the PVM holds for most of the submarkets in Hong Kong.

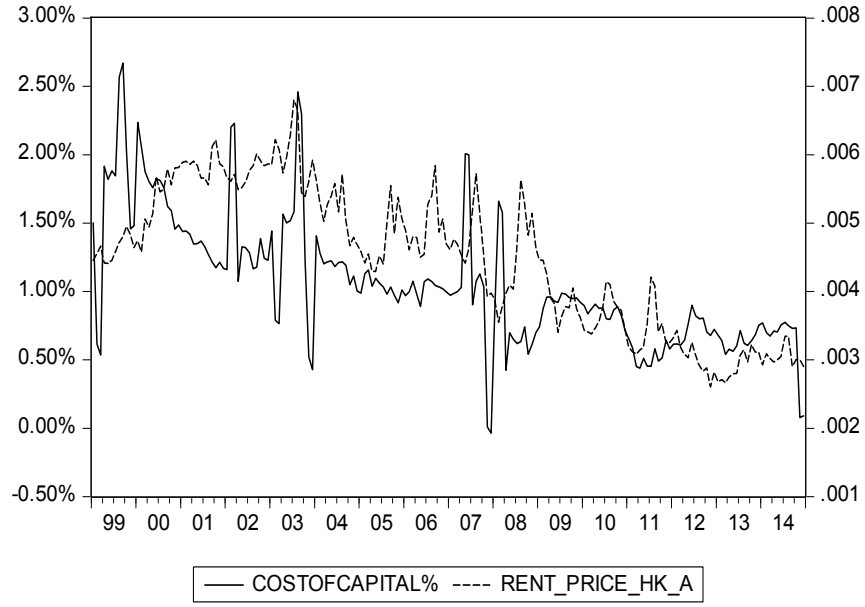

Figure 2. Costs of capital vs. rent-price ratios for HK_A submarket (1999M1 - 2014M12)

\subsection{Part Two}

Here we first assess whether the domino effects described by Ho, et al. (2008) also extend across different areas. While our tests demonstrate the rapidity of their transmissions (indicated by the lag of one month selected by SIC), those on the dominos produce diverse performance per area. As shown in Table 3, dominos along the quality continuum only seem more pronounced in NT. In HK, almost only bi-directional causalities can be observed, while ambiguous results recorded for KWN. To further confirm the existence of such effects on a territory-wide basis, we have even attempted to replicate what Ho, et al. (2008) did, using our monthly RPI series in the first data set (or even quarterly RPI series outside our data sets, which are available from the author upon request). (Note 12) Still, our findings do not concur with theirs. According to ours, all knock-on effects among classes are bi-directional in nature (or nonexistent using the aforesaid quarterly data). (Note 13) What is implicit here is that the conclusions are very sensitive to the sample period. 
Table 3. Pairwise Granger-causality test statistics on intraarea domino effects

\begin{tabular}{|c|c|c|c|c|}
\hline $\begin{array}{l}\text { Quadvariate } \\
\text { VAR Lag } p\end{array}$ & Null Hypothesis & F-Statistic & Probability & Causality \\
\hline \multirow[t]{2}{*}{1} & DLHK_B_RP does not Granger Cause DLHK_A_RP & $11.9387 * * *$ & 0.0007 & $\mathrm{~A} \leftrightarrow \mathrm{B}$ \\
\hline & DLHK_A_RP does not Granger Cause DLHK_B_RP & $14.9340 * * *$ & 0.0002 & \\
\hline \multirow[t]{2}{*}{1} & DLHK_C_RP does not Granger Cause DLHK_A_RP & $8.75324 * * *$ & 0.0035 & $\mathrm{~A} \leftrightarrow \mathrm{C}$ \\
\hline & DLHK_A_RP does not Granger Cause DLHK_C_RP & $3.91863 * *$ & 0.0492 & \\
\hline \multirow[t]{2}{*}{1} & DLHK_D_RP does not Granger Cause DLHK_A_RP & $3.37979^{*}$ & 0.0676 & $\mathrm{~A} \leftrightarrow \mathrm{D}$ \\
\hline & DLHK_A_RP does not Granger Cause DLHK_D_RP & $10.6627 * * *$ & 0.0013 & \\
\hline \multirow[t]{2}{*}{1} & DLHK_C_RP does not Granger Cause DLHK_B_RP & $7.55396^{* * *}$ & 0.0066 & $\mathrm{~B} \leftrightarrow \mathrm{C}$ \\
\hline & DLHK_B_RP does not Granger Cause DLHK_C_RP & $22.6744 * * *$ & $4 \times 10^{-6}$ & \\
\hline \multirow[t]{2}{*}{1} & DLHK_D_RP does not Granger Cause DLHK_B_RP & 0.56579 & 0.4529 & \\
\hline & DLHK_B_RP does not Granger Cause DLHK_D_RP & $13.6123 * * *$ & 0.0003 & $\mathrm{~B} \rightarrow \mathrm{D}$ \\
\hline \multirow[t]{2}{*}{1} & DLHK_D_RP does not Granger Cause DLHK_C_RP & $5.63043 * *$ & 0.0187 & $\mathrm{C} \leftrightarrow \mathrm{D}$ \\
\hline & DLHK_C_RP does not Granger Cause DLHK_D_RP & $3.90899 * *$ & 0.0495 & \\
\hline \multirow[t]{2}{*}{1} & "DLKWN_B_RP does not Granger Cause DLKWN_A_RP & $19.2781 * * *$ & $2 \times 10^{-5}$ & $\mathrm{~B} \rightarrow \mathrm{A}$ \\
\hline & DLKWN_A_RP does not Granger Cause DLKWN_B_RP & 0.26268 & 0.6089 & \\
\hline \multirow[t]{2}{*}{1} & DLKWN_C_RP does not Granger Cause DLKWN_A_RP & $5.43683 * *$ & 0.0208 & $\mathrm{~A} \leftrightarrow \mathrm{C}$ \\
\hline & DLKWN_A_RP does not Granger Cause DLKWN_C_RP & $9.66571 * * *$ & 0.0022 & \\
\hline \multirow[t]{2}{*}{1} & DLKWN_D_RP does not Granger Cause DLKWN_A_RP & $4.16505 * *$ & 0.0427 & $\mathrm{D} \rightarrow \mathrm{A}$ \\
\hline & DLKWN_A_RP does not Granger Cause DLKWN_D_RP & 0.92403 & 0.3377 & \\
\hline \multirow[t]{2}{*}{1} & DLKWN_C_RP does not Granger Cause DLKWN_B_RP & $3.63273^{*}$ & 0.0582 & $\mathrm{~B} \leftrightarrow \mathrm{C}$ \\
\hline & DLKWN_B_RP does not Granger Cause DLKWN_C_RP & $16.1397 * * *$ & $9 \times 10^{-5}$ & \\
\hline \multirow[t]{2}{*}{1} & DLKWN_D_RP does not Granger Cause DLKWN_B_RP & 0.48817 & 0.4856 & \\
\hline & DLKWN_B_RP does not Granger Cause DLKWN_D_RP & $5.16476 * *$ & 0.0242 & $\mathrm{~B} \rightarrow \mathrm{D}$ \\
\hline \multirow[t]{2}{*}{1} & DLKWN_D_RP does not Granger Cause DLKWN_C_RP & 1.03070 & 0.3113 & \\
\hline & DLKWN_C_RP does not Granger Cause DLKWN_D_RP & $3.41227^{*}$ & 0.0663 & $\mathrm{C} \rightarrow \mathrm{D}$ \\
\hline \multirow[t]{2}{*}{1} & "DLNT_B_RP does not Granger Cause DLNT_A_RP & $8.60853 * * *$ & 0.0038 & $\mathrm{~A} \leftrightarrow \mathrm{B}$ \\
\hline & DLNT_A_RP does not Granger Cause DLNT_B_RP & $7.79179 * * *$ & 0.0058 & \\
\hline \multirow[t]{2}{*}{1} & DLNT_C_RP does not Granger Cause DLNT_A_RP & 1.26665 & 0.2618 & \\
\hline & DLNT_A_RP does not Granger Cause DLNT_C_RP & $24.9720 * * *$ & $1 \times 10^{-6}$ & $\mathrm{~A} \rightarrow \mathrm{C}$ \\
\hline \multirow[t]{2}{*}{1} & DLNT_D_RP does not Granger Cause DLNT_A_RP & 0.94853 & 0.3314 & \\
\hline & DLNT_A_RP does not Granger Cause DLNT_D_RP & $4.88575 * *$ & 0.0283 & $\mathrm{~A} \rightarrow \mathrm{D}$ \\
\hline \multirow[t]{2}{*}{1} & DLNT_C_RP does not Granger Cause DLNT_B_RP & 0.21861 & 0.6406 & \\
\hline & DLNT_B_RP does not Granger Cause DLNT_C_RP & $18.7963 * * *$ & $2 \times 10^{-5}$ & $\mathrm{~B} \rightarrow \mathrm{C}$ \\
\hline \multirow[t]{2}{*}{1} & DLNT_D_RP does not Granger Cause DLNT_B_RP & 0.28042 & 0.5971 & $\mathrm{n} / \mathrm{a}$ \\
\hline & DLNT_B_RP does not Granger Cause DLNT_D_RP & 1.60064 & 0.2074 & \\
\hline \multirow[t]{2}{*}{1} & DLNT_D_RP does not Granger Cause DLNT_C_RP & $8.31866^{* * *}$ & 0.0044 & $\mathrm{D} \rightarrow \mathrm{C}$ \\
\hline & DLNT_C_RP does not Granger Cause DLNT_D_RP & 0.96362 & 0.3275 & \\
\hline
\end{tabular}

$*, * *$ and $* * *$ indicate significance at the critical value of $10 \%, 5 \%$ and $1 \%$, respectively. 
Testings on the ripple effects, on the other hand, have uncovered more meaningful implications. Table 4 sets out all summary statistics on the ripples, which can be summarized as: class A (NT $\rightarrow$ KWN $\leftrightarrow$ HK); class B (NT $\leftrightarrow$ $\mathrm{KWN} \rightarrow \mathrm{HK}$ ); class $\mathrm{C}(\mathrm{HK} \rightarrow \mathrm{NT} \rightarrow \mathrm{KWN}$ ); class $\mathrm{D}(\mathrm{KWN}$ and $\mathrm{NT} \rightarrow \mathrm{HK}$, with $\mathrm{KWN}$ and NT being independent). Interestingly, a discernible pattern behind such effects has emerged: as the class moves up the ladder (from A to B to $\mathrm{C}$ ), the origin of price change tends to shift through an area continuum, following the ordering of NT $\rightarrow \mathrm{KWN} \rightarrow$ HK. The four explanations by Meen (1999) might shed some light on this. With Hong Kong such a densely populated small city, it seems not convincing enough to declare that prices differ in areas because of different economic growth rates. Since housing units can be purchased for residence and also investment purposes, household migration, equity transfer and spatial arbitrage are all possible underlying reasons for the phenomenon. The real driving forces behind this are uncertain and deserve further investigation in future. Intuitively, this may partly be elucidated by average price patterns in the three areas. The intraclass prices in HK (NT) are traditionally the highest (lowest), with KWN's lying in-between. Households targeting at small-sized units are usually those with lower affordability. Naturally they might regard NT as their priority area because they have fewer choices. On the contrary, those higher-income groups might be more interested in larger-sized units. As they are more flexible financially, they would like to consider the KWN area as well. The same logic extends to even larger-sized, more expensive units in the HK area. However, for class D, our empirical results are somewhat difficult to interpret plausibly. That might be the evidence that the markets for large-sized units in KWN and NT are rather segmented with heterogeneous housing needs. And price changes in HK are preceded by both KWN and NT.

Table 4. Pairwise Granger-causality test statistics on intraclass ripple effects

\begin{tabular}{|c|c|c|c|c|}
\hline $\begin{array}{c}\text { Trivariate } \\
\text { VAR Lag } p\end{array}$ & Null Hypothesis & F-Statistic & Probability & Causality \\
\hline \multirow[t]{2}{*}{1} & DLKWN_A_RP does not Granger Cause DLHK_A_RP & $6.88056^{* * *}$ & 0.0094 & $\mathrm{KWN} \leftrightarrow \mathrm{HK}$ \\
\hline & DLHK_A_RP does not Granger Cause DLKWN_A_RP & $5.60825 * *$ & 0.0189 & \\
\hline \multirow[t]{2}{*}{1} & DLNT_A_RP does not Granger Cause DLHK_A_RP & $18.9613 * * *$ & $2 \times 10^{-5}$ & $\mathrm{NT} \rightarrow \mathrm{HK}$ \\
\hline & DLHK_A_RP does not Granger Cause DLNT_A_RP & 0.39453 & 0.5307 & \\
\hline \multirow[t]{2}{*}{1} & DLNT_A_RP does not Granger Cause DLKWN_A_RP & $30.4165^{* * *}$ & $1 \times 10^{-7}$ & $\mathrm{NT} \rightarrow \mathrm{KWN}$ \\
\hline & DLKWN_A_RP does not Granger Cause DLNT_A_RP & 0.92686 & 0.3369 & \\
\hline \multirow[t]{2}{*}{1} & DLKWN_B_RP does not Granger Cause DLHK_B_RP & $21.3377 * * *$ & $7 \times 10^{-6}$ & $\mathrm{KWN} \rightarrow \mathrm{HK}$ \\
\hline & DLHK_B_RP does not Granger Cause DLKWN_B_RP & 0.73301 & 0.3930 & \\
\hline \multirow[t]{2}{*}{1} & DLNT_B_RP does not Granger Cause DLHK_B_RP & $11.1871 * * *$ & 0.0010 & $\mathrm{NT} \rightarrow \mathrm{HK}$ \\
\hline & DHK_B_RP does not Granger Cause DLNT_B_RP & 2.21792 & 0.1381 & \\
\hline \multirow[t]{2}{*}{1} & DLNT_B_RP does not Granger Cause DLKWN_B_RP & $6.74662 * *$ & 0.0101 & $\mathrm{NT} \leftrightarrow \mathrm{KWN}$ \\
\hline & DKWN_B_RP does not Granger Cause DLNT_B_RP & $3.26878^{*}$ & 0.0722 & \\
\hline \multirow[t]{2}{*}{1} & DLKWN_C_RP does not Granger Cause DLHK_C_RP & 2.10518 & 0.1485 & \\
\hline & DHK_C_RP does not Granger Cause DLKWN_C_RP & $6.08477 * *$ & 0.0145 & $\mathrm{HK} \rightarrow \mathrm{KWN}$ \\
\hline \multirow[t]{2}{*}{1} & DLNT_C_RP does not Granger Cause DLHK_C_RP & 2.16531 & 0.1428 & \\
\hline & DHK_C_RP does not Granger Cause DLNT_C_RP & $8.30585^{* * *}$ & 0.0044 & $\mathrm{HK} \rightarrow \mathrm{NT}$ \\
\hline \multirow[t]{2}{*}{1} & DLNT_C_RP does not Granger Cause DLKWN_C_RP & $4.54032 * *$ & 0.0344 & $\mathrm{NT} \rightarrow \mathrm{KWN}$ \\
\hline & DKWN_C_RP does not Granger Cause DLNT_C_RP & 0.54001 & 0.4634 & \\
\hline \multirow[t]{2}{*}{1} & DLKWN_D_RP does not Granger Cause DLHK_D_RP & $4.90280 * *$ & 0.0280 & $\mathrm{KWN} \rightarrow \mathrm{HK}$ \\
\hline & DLHK_D_RP does not Granger Cause DLKWN_D_RP & 0.07075 & 0.7905 & \\
\hline \multirow[t]{2}{*}{1} & DLNT_D_RP does not Granger Cause DLHK_D_RP & $6.55715^{* *}$ & 0.0112 & $\mathrm{NT} \rightarrow \mathrm{HK}$ \\
\hline & DLHK_D_RP does not Granger Cause DLNT_D_RP & 0.10670 & 0.7443 & \\
\hline \multirow[t]{2}{*}{1} & DLNT_D_RP does not Granger Cause DLKWN_D_RP & 0.02056 & 0.8861 & $\mathrm{n} / \mathrm{a}$ \\
\hline & DLKWN_D_RP does not Granger Cause DLNT_D_RP & 0.24836 & 0.6188 & \\
\hline
\end{tabular}

$*, * *$ and $* * *$ indicate significance at the critical value of $10 \%, 5 \%$ and $1 \%$, respectively. 
As a final check, Johansen cointegration tests are run with respect to each area, each class, and also the whole territory to ascertain if there is any long-run equilibrium relation amongst the RPs or RPIs. There are two statistics, trace test and maximum eigenvalue test, for reference in order to decide the number of cointegrating equations. Suffice here to say that any positive number means the series are cointegrated. Assuming that the series have linear trends but the cointegrating equations have intercepts without trends, Johansen tests are conducted at $5 \%$ significance levels. The resultant numbers are reported in Table 5, revealing that the series are cointegrated under all cases. Again, this contradicts the findings of Ho, et al. (2008), whereby the price indices are found not cointegrated (p. 311). (Note 14) The implications from our findings are clear: regardless of whether domino (ripple) effects can be established or not, an equilibrating force seems to exist to hold the house prices together in the long run.

Table 5. Number of cointegrating relationships under Johansen cointegration method

\begin{tabular}{|c|c|c|c|c|c|c|c|c|}
\hline & $\underline{\text { Territorywide }}$ & $\underline{\mathrm{HK}}$ & $\underline{\mathrm{KWN}}$ & $\underline{\mathrm{NT}}$ & $\underline{\text { Class A }}$ & Class B & $\underline{\text { Class } \mathrm{C}}$ & $\underline{\text { Class D }}$ \\
\hline Trace & 2 & 2 & 2 & 2 & 1 & 1 & 1 & 2 \\
\hline Max-Eigenvalue & 2 & 2 & 3 & 2 & 1 & 1 & 1 & 2 \\
\hline
\end{tabular}

The no. is decided at 5\% significance level under the assumption that the series have trends but the cointegrating equations have intercepts only. Study period: 1995M1 - 2014M12 (territorywide); 1999M1 - 2014M12 (other categories).

\section{Limitations and Conclusions}

All the variables in our data sets can be prone to measurement errors. Whilst we have managed to remove the effects of inflation, no matter how minimal they are, through deflating using the composite CPI, some measurement risks may still remain. A major drawback behind average prices and rents, as pointed out by the RVD, is that they may vary due to not only value but also quality changes. Rental and price indices, on the other hand, are designed to measure rental and price variations with quality held constant. Regrettably, besides the average prices and rents, we have no better alternatives in order to undertake intraarea and intraclass analysis (Cheung, et al., 1995). We have also raised in Empirical Findings that, for some classes in different areas, average rents are found I(0) instead of I(1). This might have eroded the credibility of the subsequent cointegration testings between prices and rents.

To the author's view, homeowner costs of capital are the one most susceptible to measurement errors. Particular attention should be paid to its constituent items. Not only have we made an unrealistic assumption that risk premium is zero, but also we have used HIBOR as proxy for mortgage interest rates, which is only partially correct. (Note 15) Moreover, forecasting (rental) inflation rates is itself a daunting task. Using a simple three-month distributed lag model for the estimation is, by no means, appropriate. To keep our tasks manageable, some tentative demand-management measures by the Government (e.g., the levy of Special Stamp Duty, Buyer's Stamp Duty and doubled ad valorem stamp duty to combat speculative activities in the property market over the past several years) have been deliberately neglected. (Note 16) The zero transaction cost premise may be criticized as unjustifiable a priori. (Note 17) Despite all these, we hold the view that the movements of the costs are more important than the costs themselves. It has been demonstrated that the costs indeed move in tandem with rent-price ratios. Gallin (2008) has further studied the predictability of rent-price ratios on future price or rental returns. This is a rewarding topic, albeit not the focus of this paper, and merits further research.

To conclude our findings briefly: first, no matter whether the costs of capital are held constant or not, most of the submarkets in Hong Kong conform to the PVM for house prices under Campbell and Shiller (1987) approach, with two doubtful cases coming from higher-class units in Hong Kong Island. Meese and Wallace (1994) approach, on the other hand, tends to yield more mixed results on a territory-wide basis. With costs of capital kept constant, the PVM simply does not hold in short term. But when they are allowed to vary, although the same situation exists temporarily, in the long run the PVM is validated. Second, the domino effects along the quality tiers described by Ho, et al. (2008) prevail only weakly in the New Territories. On a territory-wide basis, they can be said to be dissipated. Nevertheless, the pattern behind the ripple effects has revealed that the origin of price change tends to shift southwards through an area continuum (NT $\rightarrow \mathrm{KWN} \rightarrow \mathrm{HK}$ ) as the class upgrades (A $\rightarrow \mathrm{B} \rightarrow \mathrm{C}$ ). Although Meen (1999) might have provided good directions on understanding this, the underlying reasons remain unknown and warrant further work. Nonetheless, whether there are appropriate and sufficient data for Hong Kong is in doubt. For instance, data related to demographic changes, household migrations, income distributions, relative supply of new private houses, and 
vacancy rates per area may be scarce or only available at very low frequency. Lastly, we also find that intraarea, intraclass or territory-wide house prices are cointegrated, irrespective of whether there are price diffusions or not.

\section{Acknowledgements}

I wish to express my gratitude to the faculty members (namely, Prof. Bingchao Shi, Guoqiang Dai, Hong Li, Hongfei Jin, Jianping Ding, Jie Zhu, Junyang Xi, Liping Chen, Ping Zou, Qiheng Han, Yao Li and Zhiguang Cao) of School of Finance, Shanghai University of Finance and Economics, for their guidance and valuable comments upon this study. Responsibility for any remaining errors lies with the author alone.

\section{References}

Brooks, C., \& Tsolacos, S. (2010). Real estate modelling and forecasting $\left(1^{\text {st }}\right.$ ed.), Cambridge University Press.

Brown, M. (2013). The history of rates in Hong Kong ( $3^{\text {rd }}$ ed.), Rating and Valuation Department, HKSAR.

Campbell, J. Y., \& Shiller, R. J. (1987). Cointegration and tests of present value models. Journal of Political Economy, 95, 1062-1088. http://dx.doi.org/10.1086/261502

Chen, P.-F., Chien, M.-S., \& Lee, C.-C. (2011). Dynamic modeling of regional house price diffusion in Taiwan. Journal of Housing Economics, 20, 315-332. http://dx.doi.org/10.1016/j.jhe.2011.09.002

Cheung, Y.-L., Tsang, S.-K., \& Mak, S.-C. (1995). The causal relationships between residential property prices and rentals in Hong Kong: 1982-1991. Journal of Real Estate Finance and Economics, 10, 23-35. http://dx.doi.org/10.1007/BF01099609

Cook, S. (2005). Regional house price behaviour in the UK: application of a joint testing procedure. Physica A, 345, 611-621. http://dx.doi.org/10.1016/S0378-4371(04)01051-9

Dougherty, A., \& Van Order, R. (1982). Inflation, housing costs, and the consumer price index. American Economic Review, 72, 154-164.

Engsted, T. (1998). Do farmland prices reflect rationally expected future rents? Applied Economics Letters, 5, 75-79. http://dx.doi.org/10.1080/758523507

Gallin, J. (2008). The long-run relationship between house prices and rents. Real Estate Economics, 36, 635-658. http://dx.doi.org/10.1111/j.1540-6229.2008.00225.x

Hacker, R. S., \& Hatemi-J, A. (2008). Optimal lag-length choice in stable and unstable VAR models under situations of homoscedasticity and ARCH. Journal of Applied Statistics, 35, 601-615. http://dx.doi.org/10.1080/02664760801920473

Hendry, D. F., \& Juselius, K. (2000). Explaining cointegration analysis: Part I. The Energy Journal, 21, 1-42. http://dx.doi.org/10.5547/ISSN0195-6574-EJ-Vol21-No1-1

Ho, L. S., Ma, Y., \& Haurin, D. R. (2008). Domino effects within a housing market: the transmission of house price changes across quality tiers. Journal of Real Estate Finance and Economics, 37, 299-316. http://dx.doi.org/10.1007/s11146-007-9070-6

Jones, C., \& Leishman, C. (2006). Spatial dynamics of the housing market: an interurban perspective. Urban Studies, 43, 1041-1059. http://dx.doi.org/10.1080/00420980600711316

Lau, A. M., \& Pearce, J. (2014). Hong Kong taxation: law \& practice (2014-15 ed.). Chinese University Press.

MacDonald, R., \& Taylor, M. P. (1993). Regional house prices in Britain: long-run relationships and short-run dynamics. Scottish Journal of Political Economy, 40, 43-55. http://dx.doi.org/10.1111/j.1467-9485.1993.tb00636.x

Meen, G. P. (1999). Regional house prices and the ripple effect: a new interpretation. Housing Studies, 14, 733-753. http://dx.doi.org/10.1080/02673039982524

Meese, R., \& Wallace, N. (1994). Testing the present value relation for housing prices: should I leave my house in San Francisco? Journal of Urban Economcs, 35, 245-266. http://dx.doi.org/10.1006/juec.1994.1015

Ong, S. E. (1994). Structural and vector autoregressive approaches to modelling real estate and property stock prices in Singapore. Journal of Property Finance, 5(4), 4-18. http://dx.doi.org/10.1108/09588689410080257

Stevenson, S. (2004). House price diffusion and inter-regional and cross-border house price dynamics. Journal of Property Research, 21, 301-320. http://dx.doi.org/10.1080/09599910500151228 
Tegene, A., \& Kuchler, F. R. (1993). Evidence on the existence of speculative bubbles in farmland prices. Journal of Real Estate Finance and Economics, 6, 223-236. http://dx.doi.org/10.1007/BF01096959

\section{Notes}

Note 1. The geographical area classification was a little bit different at that time. The whole Hong Kong territory was divided into four areas: (i) Hong Kong Island, (ii) Kowloon, (iii) New Kowloon, and (iv) New Territories. With five different size classes, there were 20 submarkets in total. Using bivariate causality analysis, there were 40 cases to consider.

Note 2. More precise definitions can be referred to from the technical notes on the web.

Note 3. In Hong Kong, the term "rates" (instead of "property tax" in US) refers to some kind of indirect tax charged at a certain percentage of the rateable value of a property; while "property tax" is chargeable on the owner for rental incomes derived from a property situated in Hong Kong. Also, mortgage interest payments are deductible from salary tax computation, always sharing the same standard rate of property tax. Hence, the assumptions in Gallin (2008; p.636) are also valid for Hong Kong. See also Appendix 1.

Note 4. Beware that for tax computation in Hong Kong, the year of assessment is from April this calendar year to March next calendar year.

Note 5. According to Campbell and Shiller (1987) reasoning (p.1074), since rent is normally known to the market at the beginning of period, no lag is required; for stocks, dividends are normally only announced at the end of the period, thus one period lag is necessary.

Note 6. A set of variables, each following integrated of order one, I(1), is said to be cointegrated if a linear combination of them is stationary, I(0). If the series are cointegrated in levels, they will also be cointegrated in $\log$ levels (Hendry \& Juselius, 2000). Thus, either the original or log-form data series in levels can be used thereafter in our cointegration testings.

Note 7. Examples include Ong (1994), Cheung, et al. (1995), Engsted (1998), Stevenson (2004), Jones and Leishman (2006), Ho, et al. (2008), Chen, et al. (2011).

Note 8. Given that the CPI for private housing rent is only available starting from 1994M10, we can only choose a lag period of no longer than 3 months so that the cost of capital series corresponds to the price and rental series.

Note 9. The only exception comes from KWN_D_RP, which is I(0); while NT_D_RP gives inconclusive results.

Note 10. HK_A_RR, HK_C_RR, KWN_C_RR, KWN_D_RR and NT_D_RR are found to be I(0); while KWN_B_RR and HK_D_RR give inconclusive results.

Note 11. The ADF, DF-GLS, PP and KPSS test statistics are $-10.0652,-9.7532,-10.5108$, and 0.2775 respectively, suggesting that the $e_{t}$ series is stationary at $1 \%$ significance level.

Note 12. Ho, et al. (2008) use quarterly PI_A, PI_B, PI_C and PI_DE series (1982Q2 to 2004Q2) without deflating in their study.

Note 13. To avoid repetition, replication test statistics are not presented here, but available from the author upon request.

Note 14. Their cointegration testing covers the period from 1987 to 2000, which is even shorter than that for the causality tests (p. 312). No explanation has been given on this, though.

Note 15. It is a common practice in Hong Kong that mortgage payments are based on HIBOR plus spread or best lending rate (BLR) minus spread.

Note 16. Reference can be made to "Measures for cooling down the overheated property market and meeting public demand for housing," IRD News Archives 2014.

Note 17. Meese and Wallace (1994) argue that the PVM can be violated temporarily because of substantial transaction costs. For example, the commission for a real estate agent in California can be as high as $6 \%$ of house price (p.258). 


\section{Appendices}

Appendix 1. Hong Kong property tax rates and rates with simplified example

\begin{tabular}{|c|c|c|c|c|}
\hline $\begin{array}{l}\text { Year of } \\
\text { Assessment } \\
\text { (April - March) }\end{array}$ & $\begin{array}{c}\text { Standard } \\
\text { Tax Rate } \\
(\%)\end{array}$ & $\begin{array}{c}\text { Rates } \\
(\%)\end{array}$ & $\begin{array}{r}\text { Property Tax Computation } \mathrm{f} \\
\text { of Assessment 2014/1 }\end{array}$ & Year \\
\hline $1994 / 97$ & 15 & 5.5 & \multirow{4}{*}{$\begin{array}{l}\text { Annual rental income } \\
\text { Less: rates paid by owner } \\
\text { @ } 5 \%\end{array}$} & $\underline{\$}$ \\
\hline $1997 / 98$ & 15 & 5 & & 100 \\
\hline 1998/99 & 15 & 4.5 & & (5) \\
\hline $1999 / 2003$ & 15 & 5 & & 95 \\
\hline $2003 / 04$ & 15.5 & 5 & $\begin{array}{l}\text { Less: statutory allowance } \\
\text { for }\end{array}$ & \\
\hline $2004 / 08$ & 16 & 5 & $\begin{array}{l}\text { repairs \& outgoings } \\
\text { @ } 20 \%\end{array}$ & (19) \\
\hline $2008 / 15$ & 15 & 5 & Net assessable value & 76 \\
\hline & & & Property tax @15\% & $\underline{11.4}$ \\
\hline
\end{tabular}

Source: Brown (2013); Lau and Pearce (2014) \& IRD

Appendix 2. Unit root (stationary) test statistics on rent-price ratios

\begin{tabular}{|c|c|c|c|c|c|c|c|c|}
\hline \multirow[b]{2}{*}{ Variables } & \multicolumn{4}{|c|}{ Level } & \multicolumn{4}{|c|}{$\underline{\text { First Difference }}$} \\
\hline & $\mathrm{ADF}$ & DF-GLS & PP & KPSS & $\mathrm{ADF}$ & DF-GLS & PP & KPSS \\
\hline RENT_PRICE_HK_A & -1.6455 & $-1.6702 *$ & -1.0422 & $1.4044 * * *$ & $-14.0325 * * *$ & $-13.1417 * * *$ & $-15.8171^{* * *}$ & 0.1935 \\
\hline RENT_PRICE_HK_B & -1.3357 & -1.2388 & -1.1501 & $1.4050 * * *$ & $-17.0699 * * *$ & $-1.7765^{*}$ & $-19.2767 * * *$ & 0.1335 \\
\hline RENT_PRICE_HK_C & -1.1125 & -0.8718 & -1.1373 & $1.4310 * * *$ & $-18.7693^{* * *}$ & $-2.0840 * *$ & $-21.2583^{* * *}$ & 0.1144 \\
\hline RENT_PRICE_HK_D & -1.0952 & -0.2177 & -1.7421 & $1.5080 * * *$ & $-13.8577 * * *$ & -0.6709 & $-26.6603 * * *$ & 0.1424 \\
\hline RENT_PRICE_KWN_A & -1.4815 & -1.4590 & -0.9638 & $1.4463^{* * *}$ & $-16.0702^{* * *}$ & -0.8862 & $-19.5926^{* * *}$ & 0.2563 \\
\hline RENT_PRICE_KWN_B & -1.7209 & -1.4920 & -1.3612 & $1.3908^{* * *}$ & $-14.6412^{* * *}$ & $-14.3274 * * *$ & $-15.8283^{* * *}$ & 0.0870 \\
\hline RENT_PRICE_KWN_C & -1.5704 & -1.3927 & -2.3808 & $1.3850 * * *$ & $-19.7608^{* * *}$ & $-2.0279 * *$ & $-21.5384 * * *$ & 0.0777 \\
\hline RENT_PRICE_KWN_D & -0.9185 & -0.7976 & -2.5224 & $1.3006^{* * *}$ & $-10.8020^{* * *}$ & $-10.5857 * * *$ & $-36.8295^{* * *}$ & 0.1521 \\
\hline RENT_PRICE_NT_A & -1.2896 & -1.3389 & -1.2896 & $1.2534 * * *$ & $-15.6939 * * *$ & $-15.7020 * * *$ & $-15.7852 * * *$ & 0.1529 \\
\hline RENT_PRICE_NT_B & -1.8119 & $-1.8421^{*}$ & -1.7528 & $1.0937 * * *$ & $-12.2065^{* * *}$ & $-13.9354 * * *$ & $-15.0299 * * *$ & 0.1084 \\
\hline RENT_PRICE_NT_C & -1.3073 & -1.1609 & -2.1094 & $1.1922 * * *$ & $-14.4712^{* * *}$ & $-14.1730^{* * *}$ & $-25.8943 * * *$ & 0.0803 \\
\hline RENT_PRICE_NT_D & -2.1891 & $-2.2005 * *$ & $-5.4848 * * *$ & $1.0902 * * *$ & $-15.7775 * * *$ & $-15.5972 * * *$ & $-41.4900^{* * *}$ & 0.1244 \\
\hline
\end{tabular}

$*$, ** and $* * *$ indicate significance at the critical value of $10 \%, 5 \%$ and $1 \%$, respectively. For KPSS test, the null hypothesis is I(0) while for other tests, it is I(1). All tests are run using test equation with intercept only. 